\title{
Global Citizenship through Global Health
}

Lee Stoner

University of North Carolina, Chapel Hill, \& Massey University

\section{Michael A. Tarrant}

University of Georgia \& University of Sunshine Coast

\section{Lane Perry}

Western Carolina University

\section{Mikell Gleason \\ University of Georgia}

\section{Daniel Wadsworth Rachel Page \\ Massey University}

\begin{abstract}
:
A collaborative study abroad program (between one New Zealand and one U.S. university) on the theme of global health has been offered three times in Australia with 59 students registered to date. The course was developed because it is believed that higher education can play a role in improving global health through the fostering of global citizenship. A global citizen is one who is aware of global issues, socially responsible, and civically engaged. From this perspective, personal health is not solely an individual, self-serving act; rather, the consequences of an individual's lifestyle behaviors have deep and wide consequences extending to the community, national, and global contexts. Our paper provides a narrative on the framework used to develop the aforementioned global health study abroad course, including (1) an initial discussion on the intricate relationship between global citizenship and global health; (2) previous evidence demonstrating that short-term study abroad has the potential to foster global citizenship; and (3) the specific process used to develop the current short-term, faculty-led, interdisciplinary, experiential study abroad course.
\end{abstract}

\section{Introduction}

Global health, alongside climate change, represents one of the greatest challenges facing contemporary societies. Of particular concern, health systems are struggling under the escalating burden of non-communicable diseases (NCDs) such as obesity, diabetes, and cardiovascular diseases (Hunter \& Reddy, 2013; WHO, 2015). Each of these NCDs has been linked to poor lifestyle choices, such as physical inactivity and unhealthy eating habits (WHO, 2013). Yet despite growing public awareness about the consequences of poor lifestyle choices, NCDs continue to rise. Based on this observation, perhaps "personal" responsibility is not the answer, and conceivably the answer is a "global" responsibility, manifested as an awareness of and commitment to global citizenship. That is, a global citizen who is aware of global health issues, and of the link between individual and global health, will be more inclined to pursue healthier lifestyle choices (Stoner, Perry, Wadsworth, Stoner, 
Lee Stoner et al.

\& Tarrant, 2014). This paper argues that institutes of higher education (IHE) can and should play a role in tackling the NCD pandemic, and that IHE can achieve this by fostering a global citizenry. Specifically, we argue that short-term study abroad courses can provide a relevant yet safe and nonthreatening learning site for students to experience, grapple with, reframe, and reflect on global issues.

In 2013, Massey University (New Zealand) partnered with the University of Georgia (UGA) (United States) to lead a global health-themed short-term, faculty-led, interdisciplinary, experiential study abroad course in Australia. The course forms part of a larger suite of courses designed to explore the role of studies abroad in nurturing a global citizenry (see Tarrant, 2010). To date, the global health course has run three times and 59 students have participated, including students from both universities. While the current sample is quantitatively insufficient, some important lessons have been learnt. The insights from these lessons may encourage the growth and development of global health-focused study abroad courses, for which the literature is currently limited (Dyjack, Anderson, \& Madrid, 2001; Hanson, 2010; Hatfield, Hecker, \& Jensen, 2009). To this end, the current article provides a narrative on the framework used to develop the aforementioned global health study abroad course, including: (1) an initial discussion on the intricate relationship between global citizenship and global health, using obesity as an exemplar; (2) previous evidence demonstrating that short-term study abroad has the potential to foster global citizenship; and (3) the specific process used to develop the current short-term global health study abroad course.

\section{Background to Global Health}

To focus the discussion in this section, obesity will be used as an exemplar NCD (Stoner \& Cornwall, 2014). The goal of this exemplar is not to encourage the development of a specific obesity-themed study abroad program, but rather to illustrate the links between individual health choices and global health outcomes.

Globally, the prevalence of obesity (defined as a BMI $\geq 30$ ) doubled between 1980 and 2008 (Kelly, Yang, Chen, Reynolds, \& He, 2008; Popkin, Adair, \& Ng, 2012). Since changes to our genetic makeup cannot fully explain this relatively recent obesity pandemic, lifestyle factors are likely culpable, including physical inactivity and unhealthy food choices. These lifestyle choices are modifiable, implying that we have the power to change this crisis through personal responsibility. However, obesity has garnered a great deal of media attention and public awareness of the health consequences is growing-yet so are obesity rates. In fact, the global prevalence of obesity is accelerating and obesity is occurring at an increasingly younger age (Olshansky et al., 2005), leading to personal, community, national, and global consequences.

At the local (individual) level, obesity is associated with a clustering of cardiovascular and metabolic complications, including hypertension, Type-2 diabetes, and subsequent cardiovascular diseases (Dietz, 2004), which lead to a decreased lifespan as well as a decreased quality of life (Brettschneider et al., 2013). It has been estimated that NCDs, including obesity, will be responsible for three times as many disability-adjusted life years as communicable diseases combined by 2030 (WHO, 2008).

At the community level, obesity and associated co-morbid complications may impair an individual both physiologically and psychologically, limiting the capacity of said individual to 
contribute to family and community (Hammond \& Levine, 2010). Moreover, if the complications of obesity become severe, the individual may require homecare, which may place a financial burden on the family and a psychological burden on the caregiver and family (Hammond \& Levine, 2010).

At the national level, obesity is exerting an growing economic burden on many nations, including productivity costs, transportation costs, and human capital costs (Hammond \& Levine, 2010). Limiting these costs to (lost) productivity, in the United States alone, it has been estimated that total productivity costs are as high as USD \$66 billion annually (Hammond \& Levine, 2010). Considering that obesity is occurring at an increasingly younger age (Stevens et al., 2012), this figure is likely to grow.

Globally, the financial consequences of the escalating burden of NCDs are considerable, with the World Economic Forum predicting that by 2030 NCDs will result in a cumulative loss in global economic output of USD $\$ 47$ trillion or 5\% of GDP (Alliance, 2014). However, arguably the most significant costs of this burden are more far-reaching; poor lifestyle choices, including those choices that contribute to obesity, have been linked to climate change and subsequent loss of biodiversity (Diaz, Fargione, Chapin, \& Tilman, 2006). For example, the use of personal vehicles to commute to school or work, instead of walking or cycling, results in environmental pollution. Poor food choices, including high meat consumption, results in inefficient use of natural resources, including land, soil, and water resources (Tukker et al., 2011). Environmental pollution and inefficient use of natural resources are contributing to the loss of biodiversity, implicating the production of food, fiber, potable water, shelter, and medicines (Diaz et al., 2006). These biodiversity-related consequences negatively impact in particular individuals and indigenous groups from low Gross Domestic Product countries, who are more directly dependent on ecosystem services (Diaz et al., 2006).

The examples above indicate some consequences of obesity from personal, community, national, and global perspectives. These examples are by no means exhaustive, and similar lists can be assembled for other NCDs. However, these examples are sufficient to highlight that personal health is not solely an individual, self-serving act; rather, the consequences of our lifestyle behaviours can be wide-ranging and widely impacting. The remainder of this article will argue that IHE can play a role in tackling the NCD pandemic by fostering "global" responsibility, manifested as global citizenship. More specifically, we will argue that short-term study abroad courses, when appropriately designed, provide a delivery mechanism that can enable global citizens who are civically engaged and capable of driving social change.

\section{What is Global Citizenship and How is It Fostered?}

Global citizenship, like other complex psychosocial concepts, is an interdisciplinary phenomenon that struggles to be framed by a single definition. Nonetheless, commonly accepted denominators of global citizenship include: (1) global awareness (understanding and appreciation of one's self in the world and of world issues); (2) social responsibility (concern for others, for society at large, and for the environment); and (3) civic engagement (active engagement with local, regional, national, and global community issues) (Schattle, 2009). In one of the most thorough reviews of the global citizenship concept in the study abroad literature, Schattle (2009) proposed that it "entails being aware of responsibilities beyond one's immediate communities and making decisions to change habits and behaviour patterns accordingly" (p. 12). 
Lee Stoner et al.

Global citizenship, and the nurturing thereof, has been previously associated with transformative learning experiences, including Mezirow's (1991) transformative learning theory (Bell, Gibson, Tarrant, Perry, \& Stoner, 2014). This includes those pedagogies that engage the student with alternative lenses, orientations, or points of view related to a complex issue, such as global health, and ultimately lead to a change in perspective (Mezirow, 1991). According to Hanson (2010), to shift perspective, the following curricular modifications are required: (1) critical reflection; (2) interdisciplinarity; and (3) engaged learning practices.

\section{Critical Reflection}

An experience without critical reflection is solely an experience, which does not necessarily provide an individual with the opportunity to shape perspective-it actually has the possibility of being mis-educative (Dewey, 1938; Wojcikiewicz, 2010). Critical reflection, as a process, engages an individual in "scratching below the surface" to be deep and accurate when determining the value of a decision, experience, or theory (Alwehaibi, 2012). An educative experience should serve as a departure point for learning, not an end result, and subsequently should present an opportunity for response or an investigation of an experientially-based question or line of inquiry ("why"). An investigation of "why" begins with thought-provoking, informed questions and focuses on inspiring learners to pursue their own learning and meaning-making. By engaging students in this process, it becomes possible to foster a shift in perspective in which students become "critically aware of how and why their assumptions have come to constrain the way they perceive, understand, and feel about their world" (Mezirow, 1991, p. 167).

An established and widely accepted approach to critical reflection within experientially-based pedagogies is the DEAL model (Ash \& Clayton, 2004). This model describes three steps following a student's engagement with an experience: (1) Description of experiences objectively; (2) Examination of experiences through reflection prompts related to learning goals; and (3) Articulation of Learning-goals for future action for improved practice and further refinement of learning. These steps occur in sequence after an experience has been completed, and DEAL can be assigned iteratively. For example, if a group of short-term study abroad students is studying local indigenous health disparities, the model could be repeated after each interaction/experience associated with their time abroad.

\section{Interdisciplinary Approach}

While there are many accepted definitions associated with interdisciplinary approaches, this approach essentially seeks to involve two or more subject areas or ways of knowing. Newell (2007) frames the approach as a two-part process associated with integration: "It draws critically on disciplinary perspectives, and it integrates their insights into a more comprehensive understanding . . - [which] can also be adapted to the creation of a new complex phenomenon" (p. 248). Addressing these complexities does not need to occur in isolation, but through integration across respective disciplines. Global public health concerns such as NCDs are undoubtedly complex and "wicked" phenomena that require multidisciplinary teams to drive complex solutions (Signal et al., 2013; Stoner et al., 2014).

\section{Engaged Learning}

Student engagement focuses on relationships between students' involvement and empiricallybased university conditions that positively impact and influence students' commitment to participate 
(Kuh, 2008). Harper and Quaye (2009) specify the definition of student engagement further by recognizing the range of measurable outcomes generated by students' involvement in educationally effective practices occurring in and out of the classroom. Similar outcomes are framed as specific items within the National Survey of Student Engagement (NSSE) and codified into four themes and ten engagement indicators measured (NSSE, 2014), as illustrated in Table 1.

According to the NSSE (and its adapted versions), which has surveyed nearly five million students across the globe over 15 years, one of the top ten practices for engaging students is Diversity/Global Learning. This specific High-Impact Practice has been described as follows:

Many colleges and universities now emphasize courses and programs that help students explore cultures, life experiences, and worldviews different from their own. These studies which may address U.S. diversity, world cultures, or both - often explore "difficult differences" such as racial, ethnic, and gender inequality, or continuing struggles around the globe for human rights, freedom, and power. Frequently, intercultural studies are augmented by experiential learning in the community and/or by study abroad. (Kuh, 2008, p. 10)

The work within the field of student engagement legitimizes and supports this pedagogical approach to experiential learning. This specific practice will be described in greater depth in the section: Case Study: Short-Term Global Health Study Abroad Course.

Table 1. National Survey of Student Engagement (NSSE) Indicators and Focus

NSSE Indicators by Themes

Theme 1: Academic challenge

Higher-order learning

Reflective \& integrative learning

Learning strategies

Quantitative reasoning

Theme 2: Learning with peers Collaborative learning

Discussions with diverse others

Theme 3: Experiences w/ faculty Student-faculty interaction
Attempts to Measure (students)

The extent to which coursework requires application, analysis, and evaluation of problems or ideas, leading to the formulation of new ideas.

The application of course material/experience to make sense of other courses, connect to social issues, challenge a personal view, or understand different perspectives.

The likelihood of reviewing notes after class, summarizing content from course lectures, texts, and assignments, and identifying key points in preparation.

The use of numerical information to examine real-world issues, to reach applied conclusions, and to evaluate what others have concluded from numerical data.

The collaborative nature of course projects, exam preparation, and study groups where students ask about and explain course material to each other.

The extent that discussions with people who are from differing races, ethnicities, economic backgrounds, and religious and political affiliations are occurring.

The level/nature of students' contact with teaching staff in/out of the classroom (e.g., committees, undergraduate research, etc.), career planning, and performance. 
Effective teaching strategies

Theme 4: Campus environment Quality interactions

Supportive environment
The likelihood that instructors clearly explained course goals, taught course sessions in an organized way, used examples, and provided feedback in a prompt manner.

The perspective that interactions with students, faculty, support staff (e.g., advisors), and administration are positive.

The emphasis the institution puts on supporting students academically, encouraging diverse contacts among students, providing health/well-being, campus activities, and assistance with non-academic responsibilities.

(Source: NSSE, 2014)

\section{Global Citizenship and Short-Term Study Abroad}

The attributes of an engaged global citizen do not just happen-they accumulate through an educative experience, conscious engagement, critical reflection, and informed application. However, a suitable delivery mechanism is required to compel a shift in perspective and engage students with a set of beliefs and values that may differ from their own current views. This shift can occur as a result of a transformative educative experience, wherein students not only reframe their own identity but also begin to negotiate a sense of belonging that "reimagines" the global community, encounters and engages diversity, and constructs citizenship as a site of struggle (Pashby, 2008).

While short-term study abroad courses have been criticized for being academically "light" (McKeown, 2009), such courses can, nevertheless, present a unique opportunity for providing action-oriented experiences that encourage reflection, critical analysis, and synthesis (Perry, Stoner, \& Tarrant, 2012). Indeed, a growing literature demonstrates that short-term study abroad courses are capable of fostering global citizenship when aligned with an appropriate academic model that includes critical reflection (Tarrant \& Lyons, 2012; Tarrant et al., 2014; Tarrant, Rubin, \& Stoner, 2014; Tarrant et al., 2011; Wynveen, Kyle, \& Tarrant, 2012). We assert that experiential, short-term study abroad courses can provide a relevant learning site for students to experience, grapple with, reframe, and reflect on issues global in nature-ultimately fostering the conditions necessary for transformative experiences that have been shown to lead to a shift in perspective, awareness, and worldview.

A word of caution must be clearly stated at this juncture. To date, the academic response to calls for greater global learning has focused on the "just do it" approach. The number of students participating in education abroad is often the primary indicator of an institution's success in achieving internationalization aims. However, we encourage faculty to incorporate field-based learning experiences and accompanying assessments into study abroad curricula and to consider their role as facilitators who foster citizens (Hanson, 2010), promoting opportunities for civic engagement, responsibility, and global awareness. The challenge, clearly, is to develop study abroad courses in a measured and effective way. Such courses must be attractive to students, including those without travel experience, yet must not turn the travel experience into a token service course of consumerism. The following section outlines an attempt to create such a course. 


\section{Case Study: Short-term Global Health Study Abroad Course}

The College of Health at Massey University (New Zealand) partnered with UGA (United States) to develop a global health-themed short-term, faculty-led, interdisciplinary, experiential study abroad course in Australia. Unlike in the United States, there are very limited experiential study abroad opportunities for students at New Zealand universities, and a limited infrastructure in which to develop such courses. Therefore, Massey on the Move was created to accomplish two specific goals: (1) establish a partnership with Discover Abroad at UGA, one of the largest providers of short-term study abroad courses in the U.S.; and (2) combine the location-specific content knowledge of Massey's College of Health with the study abroad pedagogy and infrastructure expertise of Discover Abroad, in co-developing a Global Health study abroad course.

The Discover Abroad office (www.discoverabroad.uga.edu) at UGA in the United States has provided international outbound study tours for over 4,000 U.S. students throughout the South Pacific since 2000, and is among the leading efforts for short-term courses in the United States. In 2012, Discover Abroad was recognised by the Institute of International Education as runner-up for the prestigious Heiskell Award (the highest accolade in the field of IHE) for Best Practices in Study Abroad. The courses offered by Discover Abroad are research-led, utilizing the Conceptual Framework for Exploring the Role of Studies Abroad in Nurturing Global Citizenship (Tarrant, 2010), which couples sound pedagogical content with concrete experiences (engaged learning) and critical reflection (Bell et al., 2014; Tarrant, Lyons, et al., 2014; Tarrant, Rubin, et al., 2014; Tarrant et al., 2011).

The partnership between Massey on the Move and Discover Abroad lead to the creation of a 24-day experiential course across Australia. Since 2013, and over the span of three separate courses, 59 students have been enrolled, including 10 students from New Zealand. While this is an insufficient sample to fully quantify the effects of this particular course on global citizenship and global health awareness, some initial analysis is possible (see Student Outcomes below), and some important lessons can be drawn from the conceptualization of this course that will hopefully assist in expanding the limited attempts to develop global health study abroad (Dyjack et al., 2001; Hanson, 2010; Hatfield et al., 2009). This section is broken down into four sub-sections: (1) an overview of the course, including the learning outcomes; (2) the course itinerary; (3) a description and rationale of the academic model; and (4) a description of the unique approach we are using for one of the core elements of our academic models, digital critical reflection.

\section{Introduction to the Course: Global Health-The Importance of Sustainable} Environments

The 24-day interdisciplinary, faculty-led study course examines the relationship between global health and sustainable natural and human environments, integrating diverse natural, biological, and social science perspectives. At UGA, the 6-credit interdisciplinary upper level course is cross-listed in Anthropology, Ecology, Forestry and Natural Resources, Geography, and International Affairs. At Massey University, the course is worth 30 credits (equivalent to 6 semester credits in the U.S.) in the Health Sciences, and students can split the credits to cover Science and Social Science requisites. The stated learning outcomes for the course are listed in Table 2. 
Lee Stoner et al.

Table 2. Learning Outcomes for Global Health Study Abroad Course

\# Learning Outcome

1. Evaluate relationships between human societies and their environments from multiple disciplinary perspectives, and demonstrate how human-environment interactions influence lifestyle choices and health;

2. Describe the importance of biodiverse natural environments to global health, and address impacts of human actions on natural systems, and human responses to those changes;

3. Explain how health disparities that adversely affect indigenous cultures result from colonial, historical, environmental, global, and economic factors;

4. Identify and evaluate the challenges of maintaining health that may be particular to indigenous cultures;

5. Recognize "health," "disease," "prevention," "risk reduction" and "medical treatment" as social constructs contingent on culture, environment, and global influences;

6. Identify and describe sustainable approaches that help shape a community's ability to maintain and promote health.

\section{Global Health Course Itinerary}

Australia's Sydney and Far Northeast Queensland offer ideal natural "laboratories" for comparing and contrasting cultures (notably Aboriginal Torres Strait Islanders, and Western) and environments (cities, Great Barrier Reef, rainforest, and Outback) to understand the complex relationships between global issues, including political factors and environmental sustainability, and public health. One of the greatest benefits of these locations is that Australian approaches to health care are different from what most of the students, particularly those from the United States, are accustomed to. Furthermore, recent changes in the region allow for greater Aboriginal control over the planning and deployment of health care measures, providing students a unique insight into Indigenous health and community-led decision-making processes. This is vital because students need to learn how to differentiate between "constructive" and "destructive" traditions in order to make and support decisions that enhance life in general (Bowers, 2003). In particular, since Aboriginal traditions view the natural environment as a key part of any social, cultural, or structural dimension of decision-making, this is an excellent way to introduce the students to different ways of (1) defining health, and (2) measuring health outcomes, collectively enabling students to question their own definitions of health and well-being.

The course is delivered in a modular format according to four sub-themes, which are location dependent. The course begins in Sydney, where module one examines the interactions between "Urbanization and Public Health." The effects of urbanization on public health are of particular concern to Australia, with approximately $75 \%$ of the population living in urban areas and $65 \%$ living in the eight capital cities. Of note is the fact that the majority of Aboriginal people live in these urban areas and suffer disproportionately from the effects of "lifestyle" diseases. Key questions addressed in this module include: (1) What factors contribute to or impede healthier lifestyles in urban environments?; and (2) Why may Aboriginal people be disproportionately affected? To assist students with answering these questions, lectures are provided by leading local academics, students are given a walking tour and historical perspective of Sydney by a local Indigenous elder, and visits are made to various local health services. One of the local health services we visit is the Kirkton Road Center, which provides a comprehensive range of health services, primarily to "at risk" youth, sex workers, and injecting drug users. 
In the second module, students travel to Far Northeast Queensland and the Great Barrier Reef, where they spend several days examining "the importance of natural resources to health and wellbeing." Coral reefs are among the world's most biologically diverse and productive ecosystems and supply a vast array of goods and services, including to healthcare. Coral reefs are of particular importance to many indigenous coastal communities, which depend on these ecosystems not only for most of their protein needs, but also as a primary economic driver. The Great Barrier Reef World Heritage Area, extending 2,300 km along Australia's Northeast coastline, is the largest natural feature on Earth created entirely by living organisms, and provides an excellent context to examine the direct and indirect importance of natural resources to human well-being. Key questions addressed include: (1) Why is the Great Barrier Reef dependent on neighboring ecological systems; and (2) Are natural (including marine) resources more important to the bealth of indigenous Australians than non-indigenous Australians? To assist students with answering these questions, local academics lecture on the importance of natural systems such as the Great Barrier Reef to pharmaceutical discoveries, a marine biologist accompanies the group on excursions to the reef and lectures on coral ecology and threats to reef systems, and the students complete a group research project that requires them to collect data on various indicators of "reef health."

For the third module, students travel to the Daintree Rainforest, where they spend a number of days investigating the relationships between "climate change, biodiversity and indigenous health." The cultural dimension of health decision-making is woven throughout the course. The goal is to elaborate on different ways of defining health, some of which include maintaining a close relationship to the local natural environment, but also to show them that they too "have culture," meaning they too make decisions based on their own cultural understanding of the world, and of what is right and normal. Just as Aboriginal health and well-being may come through maintenance of their cultural practices, so may Western health and well-being be determined by factors beyond biology. At the same time, structural impediments and social determinants, such as a lack of basic infrastructure, lower socio-economic status, and chronic health problems, contribute to the lower resiliency of many communities. Key questions addressed include: (1) In what ways do climate change and biodiversity loss impact on the bealth and well-being of indigenous and non-indigenous Australians? The module also includes a group research project that requires students to investigate the ecosystem services provided by various fauna. To assist students with answering these questions, an ecologist accompanies the group and lectures on rainforest ecology and threats to the health of rainforests, a visit is made to an interpretive facility called the Daintree Discovery Centre, and we visit a remote healthcare facility.

For the final module, students travel to Tyrconnell (Outback) and Atherton Tablelands (Outbush), where we critically examine strategies for "improving indigenous health." Here we explore Western approaches to health from cultural, economic, and environmental perspectives and make comparisons with Aboriginal perspectives on sustaining healthy communities and environments. These remote locations are beneficial too, in that they provide the space and time necessary to process information (critical reflection). During this time, students are able to "unpack" what they are learning, through group discussions, planned group reflection, and personal reflection time. Key questions addressed include: (1) Why have healthcare interventions had limited success among indigenous groups? and (2) What considerations need to be made when devising strategies to improve the bealth of indigenous populations? To assist students with answering these questions, students spend two nights at a 
Lee Stoner et al.

farmstay, and two nights in the outback on a former gold-mining station, where they learn about the challenges of living and receiving healthcare remotely, and visit the Apunapima Cape York Health Council, where the Chief Executive Office discusses the health and well-being challenges facing local Indigenous people and gives his thoughts on the role of central government versus local control (Abdolhosseini et al., 2015).

\section{Global Health Course Academic Model}

Given the complexity of the latent construct of global citizenship, there is unlikely to be a "one-size-fits-all" pedagogical approach. However, in order for IHE to identify an appropriate model, there must first be a philosophical platform on which to place the building blocks. As mentioned above, the current global health course is delivered in a modular format according to four sub-themes, which are location dependent i.e., experiential (see itinerary above). Each subtheme addresses relatively complex ecological, social, and cultural issues related to global health, and is comprised of a short narrative/introduction, a series of readings, field activities, service learning, seminars, and a collection of classroom lectures from traveling faculty and local experts (i.e., from local universities, government agencies, non-government organizations, organizations, etc.). Modules consist of a series of essays, group debates, science projects, and critical reflection. There is also an iterative thematic essay, focused on "understanding the meaning of progress" (sustainability, values, and the triple-bottom line), and a final two-hour, open-book exam that addresses interconnections between key concepts explored throughout the course. Finally, one week after the end of the course, students deliver a three-minute critical reflection video that addresses the same topic as the thematic essay.

While the module approach outlined above may seem disparate, the course content and the style of teaching are iterative. More specifically, building upon the theoretical framework offered by Dewey (1938) and Kolb (1984), the course employs a simple pedagogical primacy, known as the three Ds: Directing, Discussing, Delegating, with each " $D$ " representing a unique style of learning (Thornton, 2013). Initially, the educator adopts the Directive style, telling the students what to do, how to do it, and when it needs to be done. For example, through this style the educator will raise awareness about the global rise in NCDs, including obesity, providing a knowledge base to build upon (global citizenship criteria 1: awareness of global issues).

Following the Directive style, the Discussant style is used to frame concept(s) with challenging questions to guide discussion and illuminate the students' biases and worldview, and attempts to challenge preconceived notions and how they came to be. For example, the educator will raise awareness about the consequences of lifestyle-driven obesity, and ask the students to begin to question how their health actions and lifestyle choices impact the global community (global citizenship criteria 2: social responsibility). Finally, the facilitator adopts the Delegation style, whereby the challenging questions begin to come from the students themselves. As the task experience increases and the students become more empowered and civically engaged (global citizenship criteria 3), this is where critical reflection becomes imperative for student learning. However, the mode of critical reflection must enable students to enter a space where they are emboldened to become intimate with their inner dialogue. 


\section{Critical Reflection Model: The Unique Value of Digital Storytelling}

For their final assignment, students deliver a three-minute digital story focusing on the notion of progress, as a novel means of critical reflection. As discussed above, fostering global citizenship requires a shift in perspective, and a key component in this shift is critical reflection (Mezirow, 1991). Previous work from our group demonstrates that traditional forms of critical reflection can and do work in the context of short-term study abroad (Bell et al., 2014; Tarrant, Lyons, et al., 2014; Tarrant, Rubin, et al., 2014; Tarrant et al., 2011). However, over the course of leading more than 5,000 students on short-term study abroad courses, our team has become acutely aware that communication and the presentation of information has been transformed in many ways over the past decade. Whether students are speaking/writing in "text-language," "poking" each other on Facebook, or offering opinions via Twitter, the lines have blurred between what is known and how it is communicated. This realization is particularly relevant when facilitating environments where personal exploration and critical reflection are vanguard.

We argue that reflective experiences can be further enhanced by using technologies and services with which many students are intimately familiar and which they use on a daily basis (Figure 1). In this regard, digital storytelling can provide students with a louder, clearer voice, utilizing a presentational form (Taylor \& Ladkin, 2009) to reflectively articulate themselves and develop the foundation of a civically engaged citizen.

Figure 1. Pathway from Experience to Global Citizenship
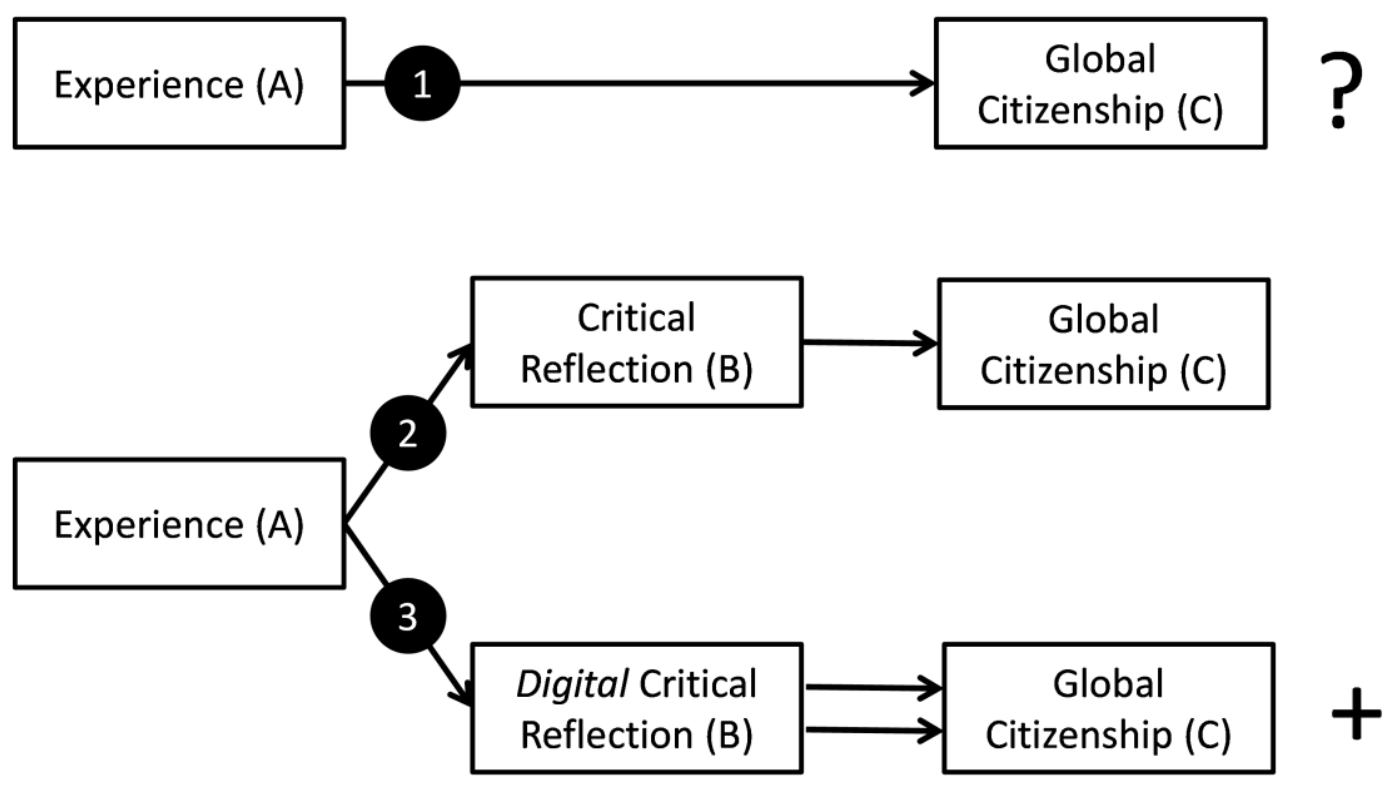

Note. Pathway 1 presents the "just do it" approach, where it is expected that experiential education (A) is sufficient to foster global citizenship (C). Pathway 2 couples experiential education (A) with a traditional critical reflection (e.g., paper-based) (B) approach, an approach demonstrated to lead to global citizenship (C) within the context of study abroad (Tarrant \& Lyons, 2012; Tarrant, Rubin, et al., 2014; Wynveen et al., 2012). Pathway 3 replaces traditional critical reflection with digital critical reflection (C), an opportunity to meet learners on the platforms and forums where they live, communicate, and already engage and subsequently enhance reflective process. 
Lee Stoner et al.

Digital stories, when compared to traditional reflective journals, have been demonstrated to be more indicative of the impact experiences had on students' learning and competency (Walters, Green, Liangyan, \& Walters, 2011). Walters et al. (2011) state: "While journals recorded a catalogue of events, the digital stories, even at the lowest-level of reflection, were more indicative of the impact of the experience ... than journals" (p. 49). Moreover, this forum has greater potential to take the learning experience beyond the classroom, helping students connect with the global community and potentially become truly engaged global citizens empowered with voices to evoke change (for further review, see Perry et al., 2015).

\section{Student outcomes}

We can use both quantitative (survey assessment) and qualitative (open-ended survey questions, digital stories) methods of assessment not only to piece together effects of short-term study abroad on student learning outcomes, but also to improve our programs and target those outcomes more specifically. Quantitatively, Discover Abroad at UGA is making an attempt to quantify student learning outcomes related to short-term study abroad programs through the collection of pre- and post-program survey data. With respect to global citizenship, the survey uses the Global Perspectives Inventory (GPI) (Braskamp, Braskamp, \& Engberg, 2014), which attempts to measure domains "deemed central to the growth and development of college-aged (18 to 24 year old) students" (Tarrant, Rubin, \& Stoner, 2015, p. 69) (see Table 3). While there are many tools available for assessing intercultural and global competence, the GPI focuses on more than just intercultural awareness or sensitivity, and is widely accepted as a measurement tool for global citizenship/engagement in study abroad and international education (Tarrant et al., 2015). The three domains - cognitive (how do I know?), intrapersonal (who am I?), and interpersonal (how do I relate to others?) —are tested through six sub-scales, two for each domain (Table 3). These dimensions relate closely to the definition of global citizenship asserted in this paper, and, as used by UGA, are part of a larger survey instrument that includes measures of sustainability and environmental concern (Tarrant \& Lyons, 2012; Tarrant, Rubin, et al., 2014).

Table 3. The Three Domains and Six Sub-Scales of the Global Perspectives Inventory (adapted from Braskamp, Braskamp, \& Engberg, 2014)

\begin{tabular}{lll}
\hline Domain & Dimension & Characteristics \\
\hline Cognitive & Knowing & Complexity of viewpoint, taking into consideration multiple cultural perspectives \\
& Knowledge & Awareness and understanding of other cultural perspectives and their global effects \\
Intrapersonal & Identity & Awareness of self-identity and purpose in life \\
& $\begin{array}{l}\text { Affect } \\
\text { Interpersonal }\end{array}$ & $\begin{array}{l}\text { Social } \\
\text { interactions }\end{array}$ \\
& $\begin{array}{l}\text { Social } \\
\text { responsibility }\end{array}$ & Engagement with those who are different from oneself, cultural sensitivity \\
\hline
\end{tabular}

While the primary purpose of this paper is to provide a narrative on the framework used to develop a global health program, to provide a path for others to follow, some outcome data is useful for supporting this narrative. For the purpose of this paper, data from the GPI survey described above was available for 41 out of 42 students who participated in the Global Health programs of 
2013 ( $n=18$, female $=13$, mean age $=22$ years) and $2014(n=24$, female $=20$, mean age $=20$ years). The results are shown in Table 4. Although the specific design used in this evaluation does not permit for the causal attribution of the sources of student learning, three of the six dimensions significantly improved following completion of the course. There were small-medium effect changes: Cognitive Knowledge $(d=0.5)$, Intrapersonal Effect $(d=0.4)$, and Interpersonal Social Interaction $(d=0.5)$ at post-test vs. pre-test.

Table 4. Paired Sample T-Test of Student: Pre-test vs. Post-test Scores on Six Dimensions of the Global Perspectives Inventory

\begin{tabular}{|c|c|c|c|c|c|c|c|}
\hline & \multicolumn{2}{|l|}{ Pre-test } & \multicolumn{2}{|l|}{ Post-test } & \multirow[b]{2}{*}{$\mathrm{t}$} & \multirow[b]{2}{*}{$\mathrm{P}$} & \multirow[b]{2}{*}{$d$} \\
\hline & $\mathrm{X}$ & SD & $\mathrm{X}$ & SD & & & \\
\hline Cognitive Knowing & 27.1 & 3.3 & 28.0 & 4.2 & 1.45 & 0.151 & 0.2 \\
\hline Cognitive Knowledge & 17.6 & 2.9 & 18.9 & 2.8 & 3.88 & $<0.01$ & 0.5 \\
\hline Intrapersonal Identity & 25.1 & 2.8 & 25.4 & 3.0 & 1.17 & 0.253 & 0.1 \\
\hline Intrapersonal Affect & 32.1 & 2.9 & 33.2 & 3.1 & 2.49 & 0.018 & 0.4 \\
\hline Interpersonal Social Responsibility & 19.3 & 3.3 & 19.3 & 3.7 & 0.16 & 0.875 & 0.0 \\
\hline Interpersonal Social Interaction & 24.3 & 3.9 & 26.1 & 3.2 & 3.99 & $<0.01$ & 0.5 \\
\hline
\end{tabular}

$\mathrm{X}=$ mean $\mathrm{SD}=$ standard deviation; $\mathrm{t}=$ paired $\mathrm{t}$-test $\mathrm{P}=\mathrm{p}$ value, $d=$ Cohen's d (effect size)

\section{Lessons Learned, Future Direction, and Conclusions}

In this article we have argued that IHE can and should play a role in the fight against the global health pandemic. We have also argued that institutes of $\mathrm{HE}$ can answer this call by developing educative programs that foster global citizens who realize that personal health is not solely an individual, self-serving act. However, responding to this reality requires a considerable increase in the global literacy of the typical college graduate. One such pedagogical model includes short-term, faculty-led, experiential study abroad courses. In the process of developing such a course, our team has had to overcome a number of academic administrative obstacles, particular in the context of New Zealand where the infrastructure for study abroad is minimal. Two major obstacles are discussed in this section.

The first obstacle is: Why study overseas and not locally? Indeed, it is more than likely that a student will not need to travel beyond the local community to experience the NCD pandemic. As such, locally-based service learning could be used as a medium to provide students with meaningful, engaging learning experiences (Kuh, 2008; O’Steen \& Perry, 2012). We strongly agree with this proposition, but at the same time argue that study abroad can be particularly powerful if it exposes students to realities outside their comfort zone, and challenges the learner to acquire new perspectives in order to gain a more complete and complex understanding. Nonetheless, campusbased educational models could be particularly powerful if coupled with international education; by utilizing local contexts to engage students with global issues, there is potential for sustained student engagement following disorientating international experiences. The cross-connections and additive value of service learning study abroad warrants further attention.

The second obstacle is: Can short-term study abroad courses provide sufficient exposure to elicit deep learning? For example, in the current course we spend only four days in the Daintree 
Rainforest exploring the relationships between "climate change, biodiversity, and indigenous health." However, the goal of the current course is not to make students content experts, which cannot be accomplished in a double-credit course. Rather, the goal is to disorientate students by providing academically driven experiences that challenge the way students perceive the world. Equally as important, and using the Daintree portion of the course to provide context, this may be the only realistic opportunity for many students to visit indigenous communities and health services, and listen to personal stories pertaining to how climate change is affecting their health and well-being. Such personal stories may help to directly connect taught material to reality, and is arguably more likely to elicit a change in perspective and encourage further learning and engagement.

In summary, short-term, faculty-led, interdisciplinary, experiential study abroad courses, if coupled with an appropriate pedagogical model, can foster global citizenship by providing transformative learning experiences that lead to a shift in perspective, awareness, and worldview. Given that global health represents one of the greatest challenges facing contemporary societies, a global citizenship competency, within the context of global health, should become an integral component of a university's core curriculum, alongside fundamental disciplines such as history or science.

\section{References}

Abdolhosseini, P., Bonner, C., Montano, A., Young, Y.-Y., Wadsworth, D., Williams, M., \& Stoner, L. (2016). Should the governments of 'developed' countries be held responsible for equalizing the indigenous health gap? Global Health Promotion, 23(4), 70-72. https://doi.org/10.1177/1757975915574255

Alliance, T. N. (2014). UN NCD Review: 10-11 July 2014 Retrieved from https://www.uicc.org/un-ncdreview-10-11-july-2014

Alwehaibi, H. (2012). Novel program to promote critical thinking among higher education students: Empirical study from Saudi Arabia. Asian Social Science, 8(11), 193-204.

Ash, S. L., \& Clayton, P. H. (2004). The articulated learning: An approach to reflection and assessment. Innovative Higher Education, 29, 137-154.

Heather L. Bell, Heather J. Gibson, Michael A. Tarrant, Lane G. Perry III \& Lee Stoner (2016) Transformational learning through study abroad: US students' reflections on learning about sustainability in the South Pacific, Leisure Studies, 35:4, 389-405, https://doi.org/10.1080/02614367.2014.962585

Bowers, C. A. (2003). Mindful conservatism: rethinking the ideological and educational basis of an ecologically sustainable future. Lanham, MD: Rowman \& Littlefield.

Braskamp, L., Braskamp, D. C., \& Engberg, M. E. (2014). Global Perspective Inventory (GPI): Its Purpose, Construction, Potential Uses, and Psychometric Characteristics. Retrieved from http://gpi.central.edu.

Brettschneider, C., Leicht, H., Bickel, H., Dahlhaus, A., Fuchs, A., Gensichen, J., . . Zieger, M. (2013). Relative impact of multimorbid chronic conditions on health-related quality of life - results from the multicare cohort study. PLoS One, 8(6), e66742.

Dewey, J. (1938). Experience and education. New York: Collier Books.

Diaz, S., Fargione, J., Chapin, F. S., 3rd, \& Tilman, D. (2006). Biodiversity loss threatens human wellbeing. PLoS Biol, 4(8), e277.

Dietz, W. H. (2004). Overweight in childhood and adolescence. New England Journal of Medicine, $350(9), 855-857$.

Dyjack, D., Anderson, B., \& Madrid, A. (2001). Experiential Public Health Study Abroad Education: Strategies for Integrating Theory and Practice. Journal of Studies in International Education, 5(3), 244-254. 
Hammond, R. A., \& Levine, R. (2010). The economic impact of obesity in the United States. Diabetes Metabolic Syndrome, and Obesity, 3, 285-295.

Hanson, L. (2010). Global Citizenship, Global Health, and the Internationalization of Curriculum: A Study of Transformative Potential. Journal of Studies in International Education, 14(1), 70-88.

Harper, S. R., \& Quaye, S. J. (2009). Beyond sameness, with engagement and outcomes for all: an introduction. In S. R. Harper \& S. J. Quaye (Eds.), Student engagement in higher education: theoretical perspectives and practical approaches for diverse populations (pp. 1-16). New York: Routledge.

Hatfield, J. M., Hecker, K. G., \& A.E., J. (2009). Building Global Health Research Competencies at the Undergraduate Level. Journal of Studies in International Education, 13(4), 509-521.

Hunter, D. J., \& Reddy, K. S. (2013). Noncommunicable diseases. New England Journal of Medicine, 369(14), 1336-1343.

Kelly, T., Yang, W., Chen, C. S., Reynolds, K., \& He, J. (2008). Global burden of obesity in 2005 and projections to 2030. International Journal of Obesity (London), 32(9), 1431-1437.

Kuh, G. (2008). High-impact educational practices: What they are, who has access to them, and why they matter. Washington, DC: Association of American Colleges \& Universities.

McKeown, J. S. (2009). The first time effect: the impact of study abroad on college student intellectual development. Albany, NY: State University of New York Press.

Mezirow, J. (1991). Transformative dimensions of adult learning (1st ed.). San Francisco: Jossey-Bass.

Newell, W. H. (2007). Decision making in interdisciplinary sciences. In G. F. Morçöl (Ed.), Handbook of decision making (pp. 245-263). New York: Taylor \& Francis.

NSSE. (2014). From Benchmarks to Engagement Indicators and High-Impact Practices. Indiana: National Survey of Student Engagement.

O'Steen, B., \& Perry, L. (2012). Service-learning as a responsive and engaging curriculum: A higher education institution's response to natural disaster. Curriculum Matters, 8, 171-185.

Olshansky, S. J., Passaro, D. J., Hershow, R. C., Layden, J., Carnes, B. A., Brody, J., Ludwig, D. S. (2005). A potential decline in life expectancy in the United States in the 21st century. New England Journal of Medicine, 352(11), 1138-1145.

Perry, L., Stoner, L., Schleser, M., Stoner, K., Wadsworth, D., Page, R., \& Tarrant, M. A. (2015). Digital Mediums as Reflective Tools: Finding Appropriate Spaces for Students to Get Introspective. Compare: A Journal of Comparative and International Education, 42(2), 323-330.

Perry, L., Stoner, L., \& Tarrant, M. A. (2012). More than a vacation: short-term study abroad as a critically reflective, transformative learning experience. Creative Education, 3(5), 679-683.

Popkin, B. M., Adair, L. S., \& Ng, S. W. (2012). Global nutrition transition and the pandemic of obesity in developing countries. Nutrition Review, 70(1), 3-21.

Schattle, H. (2009). Global citizenship in theory and practice. In R. Lewin (Ed.), The handbook of practice and research in study abroad: higher education and the quest for global citizenship (pp. 318). London: Routledge.

Signal, L. N., Walton, M. D., Ni Mhurchu, C., Maddison, R., Bowers, S. G., Carter, K. N., . . Pearce, J. (2013). Tackling 'wicked' health promotion problems: a New Zealand case study. Health Promotion International, 28(1), 84-94.

Stevens, G. A., Singh, G. M., Lu, Y., Danaei, G., Lin, J. K., Finucane, M. M., . . . Ezzati, M. (2012). National, regional, and global trends in adult overweight and obesity prevalences. Popular Health Metrics, 10(1), 22.

Stoner, L., \& Cornwall, J. (2014). Did the American Medical Association make the correct decision classifying obesity as a disease? Australasian Medical Journal, 7(11), 462-464.

Stoner, L., Perry, L., Wadsworth, D., Stoner, K. R., \& Tarrant, M. A. (2014). Global citizenship is key to securing global health: the role of higher education. Preventative Medicine, 64, 126-128.

Tarrant, M. A., \& Lyons, K. (2012). The effect of short-term educational travel programs on environmental citizenship. Environmental Education Research, 18(3), 403-416. 
Tarrant, M. A., Lyons, K., Stoner, L., Kyle, G., Wearing, S., \& Poudyal, N. (2014). Global Citizenry, Educational Travel and Sustainable Tourism: Evidence from Australia and New Zealand. Journal of Sustainable Tourism, 403-420.

Tarrant, M. A., Rubin, D., \& Stoner, L. (2014). The Added Value of Study Abroad: Fostering a Global Citizenry. Journal of Studies in International Education, 18(2), 141-161.

Tarrant, M. A., Rubin, D., \& Stoner, L. (2015). The Effects of Studying Abroad and Studying Sustainability on Global Perspectives. Frontiers: The Interdisciplinary Journal of Study Abroad, 26, 68-82.

Tarrant, M. A., Stoner, L., Borrie, W. T., Kyle, G., Moore, R. L., \& Moore, A. (2011). Educational Travel and Global Citizenship. Journal of Leisure Research, 43(3), 403-426.

Taylor, S. S., \& Ladkin, D. (2009). Understanding Arts-Based Methods in Managerial Development. Academy of Management Learning \& Education, 8(1), 55-69.

Thornton, P. (2013). Three teaching styles Retrieved Sept 30, 2013, from http://www.facultyfocus.com/articles/philosophy-of-teaching/three-teachingstyles/?utm_source=cheetah\&utm_medium=email\&utm_campaign=2013.09.30\%20Faculty $\% 20$ Foc us\%20Update

Tukker, A., Goldbohm, R., de Koning, A., Verheijden, M., Kleijn, R., Wolf, O., . . R Reuda-Cantuche, J. (2011). Environmental impacts of changes to healthier diets in Europe. Ecological Economics, 70, $1776-1788$.

Walters, L. M., Green, M. R., Liangyan, W., \& Walters, T. (2011). From Heads to Hearts: Digital Stories as Reflection Artifacts of Teachers' International Experience. Issues in Teacher Education, 20(2), 3752.

WHO. (2008). The global burden of disease: 2004 update. Geneva: World Health Organization.

WHO. (2013). Global action plan for the prevention and control of NCDs 2013-2020. Geneva: World Health Organization.

WHO. (2015). WHO highlights need for countries to scale up action on noncommunicable diseases. Retrieved March 23, 2015 from http://www.who.int/mediacentre/news/notes/2014/action-onncds/en/

Wojcikiewicz, S. K. (2010). Dewey, Peirce, and the Categories of Learning. Education and Culture, $26(2), 65-82$.

Wynveen, C. J., Kyle, G. T., \& Tarrant, M. A. (2012). Study Abroad Experiences and Global Citizenship : Fostering Proenvironmental Behavior. Journal of Studies in International Education, 16(4), 334-352. 